\title{
Modelling and control of electric vehicle power train
}

\section{Souhir Tounsi}

National School of Electronics and Telecommunications of Sfax-(SETIT): Research Unit, Sfax University, Sfax, Tunisia

\section{Email address:}

souhir.tounsi@isecs.rnu.tn

\section{To cite this article:}

Souhir Tounsi. Modelling and Control of Electric Vehicle Power Train. American Journal of Electrical Power and Energy Systems. Special Issue: Design, Optimization and Control of Electric Vehicles: (DOCEV). Vol. 4, No. 2-1, 2015, pp. 33-41.

doi: 10.11648/j.epes.s.2015040201.15

\begin{abstract}
This paper describes the choice and the design of electric vehicles power train structure reducing considerably the energy consumption. Indeed The converter feeding the motor is naturally with IGBTs leading on the one hand to important losses and on the other hand to many control problems. This structure is replaced by another with electromagnetic switch leading to a strong reduction of the losses and to an increase of the electric motor control reliability. The power train contains an energy recuperation system during the deceleration phases, where the motor functions in generator. The motor is controlled by vector control method maintaining the current Id equal to zero, leading to the maintain of the current in phase with electromotive force, what also leads to the reduction of the energy consumption. A supper-capacity is added in parallel with the energy accumulator leads to an increase of the storage energy capacity. All these factors lead to the increase of the autonomy for a known stocked energy.
\end{abstract}

Keywords: Power Chain, Design, Battery, Converter, Thermal Model, Simulation

\section{Introduction}

Currently and in look of the strong petroleum crises, during these last decades and the problems of atmospheric pollution, the electrification of the vehicles project became a project of actuality. In this context, several works of research are thrown on this thematic [1], [2], [3], [4] and [5].

Following several works of research a single motor configuration provided with a differential is kept. The motor is with permanent magnet and sinusoidal wave-form, having an axial structure. Naturally the power converter is with IGBTs, leading to an important energy losses [6], and to many control problems: such as the floating voltage and the tail current at the commutation time and the problems of the static and dynamic latch-up requiring a complicating control system. In our case, we choices a static converter structure with electromagnetic switch leading practically to the annulment of losses and to the increase of the reliability of the control.

The power train includes an energy recuperation system during decelerations phases leading to the reduction of the energy consumption and thereafter to the increase of the autonomy.

We choices a vector control strategy fixing the electromotive force in phase with the current (Strategy Id =0) also leading to the economy of energy and thereafter the increase of the autonomy. The design of this power train takes in account of most technological constraints and others attached to reliability [6].

This paper describes the choice, the design methodology and the control strategy of this power train.

\section{Electric Vehicle Power Train Structure}

The synoptical schema of the electric vehicle power train is illustrated by figure1:

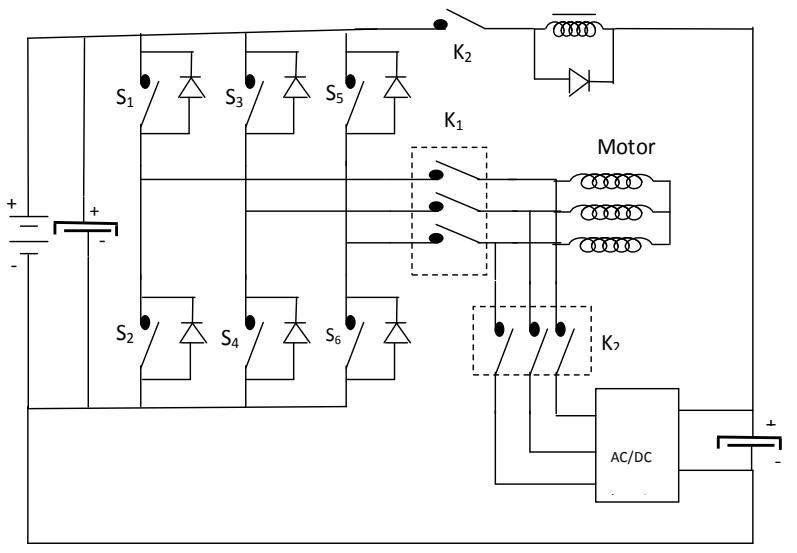

Figure 1. Electric vehicle power train structure. 
Naturally, DC/AC converter powering the motor is with IGBTs. In our case, we have chosen a structure with electromagnetic switches leading to a reduction of the energy losses. The control of these switches is assured by six generating windings. Being powered by a sufficient current, these windings attract their ferro-magnetic cores, leading to the closings of these switches according to the vector control strategy fixing the current in phase with the electromotive force $(\mathrm{Id}=0)$. At the time of their dice-power these windings free the energy stocked through a free wheel diode. Two working phases are possible:

- Working in motor phase: in this phase the $\mathrm{K} 1$ switches are closed and generating windings assures the opening and the closing of the converter's switches according to a vector control strategy reducing the energy consumption. This phase is possible for working either in accelerated phase or in constant speed. During this phase the K2 switches are open.

- Working in generating phase: this phase is possible for a working in decelerated phase. In this phase, the motor function in generator. The control system opens the switches of the static converter and the $\mathrm{K} 1$ switches. At this moment the energy recuperation system functions. In this phase, the K2 switches close itself to convert the three electromotive forces of the motor that absorbed himself according to the speed decreasing during the time on DC voltage. The recovered DC voltage is filtered by a capacitor. This voltage source is converted in a current source permitting the injection of electrons in the battery. This last is in charge thereafter. This phase is named energy recuperation phase. The duration of this phase is until the stability of the speed or the acceleration of the vehicle.

\section{Dimensioning Torque Energy Accumulator}

The energy accumulator is a coupling of several elementary batteries, whose structure is given by the figure 2 :

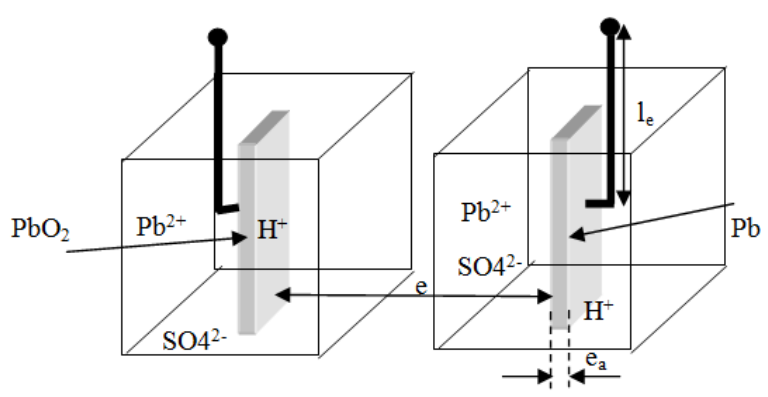

Figure 2. Elementary structure of battery.

Every element is composed of reservoirs with different electric polarity, in contact with two armatures. This structure is equivalent to a capacity temporarily charged by the quantity of charge recovered by the armature. Two electrodes permit the recuperation of the voltage generated by the battery. The whole armature more electrodes present a resistance in series with the capacity. A capacity in parallel with this resistance exists. The existence of this capacity can be explained by the polarity difference between electrode-armature and electrode output voltage contacts, what leads to the equivalent diagram of a battery element (figure 3 ):

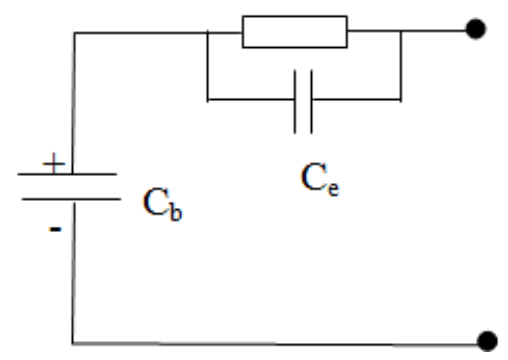

Figure 3. Model of the battery elementary structure

$$
\mathrm{C}_{\mathrm{b}}=\frac{\varepsilon \mathrm{e}}{\mathrm{S}_{\mathrm{a}}}
$$

Where $\varepsilon$ and e are respectively the permitivity and the distance of the place separating the armatures and $\mathrm{Sa}$ is the surface of the armature.

$$
\mathrm{C}_{\mathrm{e}}=\frac{\varepsilon 1_{\mathrm{e}}}{\mathrm{S}_{\mathrm{e}}}
$$

$1_{\mathrm{e}}$ and $\mathrm{S}_{\mathrm{e}}$ are respectively the length and the section of one electrode.

$$
R_{b}=2 \frac{\rho_{a}(t) e_{a}}{S}+2 \frac{\rho_{e}(t) 1_{e}}{S_{e}}
$$

Where $\rho_{\mathrm{a}}$ and $\rho_{\mathrm{e}}$ are respectively the materials resistivity of the armature and the electrode, $\mathrm{S}$ is the section of armature and ea is the armature thickness.

The number of elements in series and in parallel depends on the stocked energy and on the battery delivered voltage. We expect the coupling of a super-capacitor in parallel with the battery to increase the storage capacity of the accumulator of energy. If we disregard $\mathrm{R}_{\mathrm{b}}$ and $\mathrm{Ce}$, the energy stocked in the accumulator is deduced by the following formula:

$$
\mathrm{W}_{\mathrm{b}}=\frac{1}{2}\left(\mathrm{C}_{\mathrm{bt}}+\mathrm{C}_{\mathrm{s}}\right) \mathrm{U}_{\mathrm{b}}^{2}
$$

Where $\mathrm{C}_{\mathrm{bt}}$ and $\mathrm{Cs}_{\mathrm{s}}$ are respectively the equivalent capacities of the battery and the super-capacity and $U_{b}$ is the battery voltage.

The equation of oxydo-reduction is as follow:

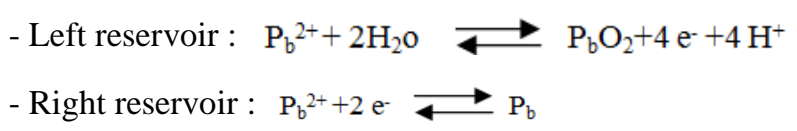

$\left[\mathrm{H}^{+}\right]$and $\left[\mathrm{P}_{\mathrm{b}}{ }^{2+}\right]$ are the molar concentrations of hydrogen and lead.

The voltage to the level of the two electrodes left and right are given by the following NRENST formula:

$$
\mathrm{E}_{\mathrm{G}}=\mathrm{E}_{\mathrm{G}}^{0}+\frac{\mathrm{R} \times \mathrm{T}}{2 \times \mathrm{A}} \times \operatorname{Ln}\left(\mathrm{P}_{\mathrm{b}}{ }^{2+}\right)
$$




$$
\mathrm{E}_{\mathrm{D}}=\mathrm{E}_{\mathrm{D}}^{0}+\frac{\mathrm{R} \times \mathrm{T}}{2 \times \mathrm{A}} \times \operatorname{Ln}\left(\frac{\left[\mathrm{H}^{+}\right]_{+}^{4}}{\left[\mathrm{P}_{\mathrm{b}}^{2+}\right]}\right)
$$

Where EG0 and ED0 are the standard voltages of the two red-ox couples, $\mathrm{T}$ is the temperature and $\mathrm{R}, \mathrm{A}$ are constants.

From where the difference of the two electrodes voltages is expressed by the following formula:

$$
\mathrm{U}_{\mathrm{e}}=\mathrm{E}_{\mathrm{D}}^{0}-\mathrm{E}_{\mathrm{G}}^{0}+\frac{\mathrm{R} \times \mathrm{T}}{2 \times \mathrm{A}} \times \mathrm{Ln}\left(\frac{\left[\mathrm{H}^{+}\right]_{7}^{4}}{\left[\mathrm{P}_{\mathrm{b}}^{2+}\right]}\right)-\frac{\mathrm{R} \times \mathrm{T}}{2 \times \mathrm{A}} \times \mathrm{Ln}\left(\left[\mathrm{P}_{\mathrm{b}}^{2+}\right)\right.
$$

At $25^{\circ} \mathrm{C}$ the voltage of one element of battery is expressed as follow:

$$
\mathrm{U}_{\mathrm{e}}=\mathrm{E}_{\mathrm{D}}^{0}-\mathrm{E}_{\mathrm{G}}^{0}+\frac{0.06}{2} \times \mathrm{Ln}\left(\frac{\left[\mathrm{H}^{+}\right]^{4}}{\left[\mathrm{P}_{\mathrm{b}}^{2+}\right]^{2}}\right)
$$

The number of elements to couple in series to get the wished battery voltage is deducted therefore from the following formula:

$$
\mathrm{n}_{\mathrm{es}}=\frac{\mathrm{U}_{\mathrm{b}}}{\mathrm{E}_{\mathrm{D}}^{0}-\mathrm{E}_{\mathrm{G}}^{0}+\frac{0.06}{2} \times \mathrm{Ln}\left(\frac{\left[\mathrm{H}^{+}\right]^{4}}{\left[\mathrm{P}_{\mathrm{b}}^{2+}\right]^{2}}\right)}
$$

The number of elements to couple in parallel to complete the stocked energy reserves is expressed as follow:

$$
\mathrm{n}_{\mathrm{ep}}=\frac{\mathrm{W}_{\mathrm{b}}-\left(\frac{1}{2} \times \mathrm{n}_{\mathrm{es}} \times \mathrm{C}_{\mathrm{e}} \times \mathrm{U}_{\mathrm{e}}^{2}+\frac{1}{2} \times \mathrm{C}_{\mathrm{s}} \times \mathrm{U}_{\mathrm{b}}^{2}\right)}{\frac{1}{2} \times \mathrm{C}_{\mathrm{e}} \times \mathrm{U}_{\mathrm{e}}^{2}}
$$

\section{Design Methodology of Electric Motor}

The chosen of electric motor structures is oriented to permanent magnets, axial flux and modular structure with more combination and its radial flux equivalent motor [7].

Figure 4 illustrates one configuration with axial flux and its radial flux equivalent structure:

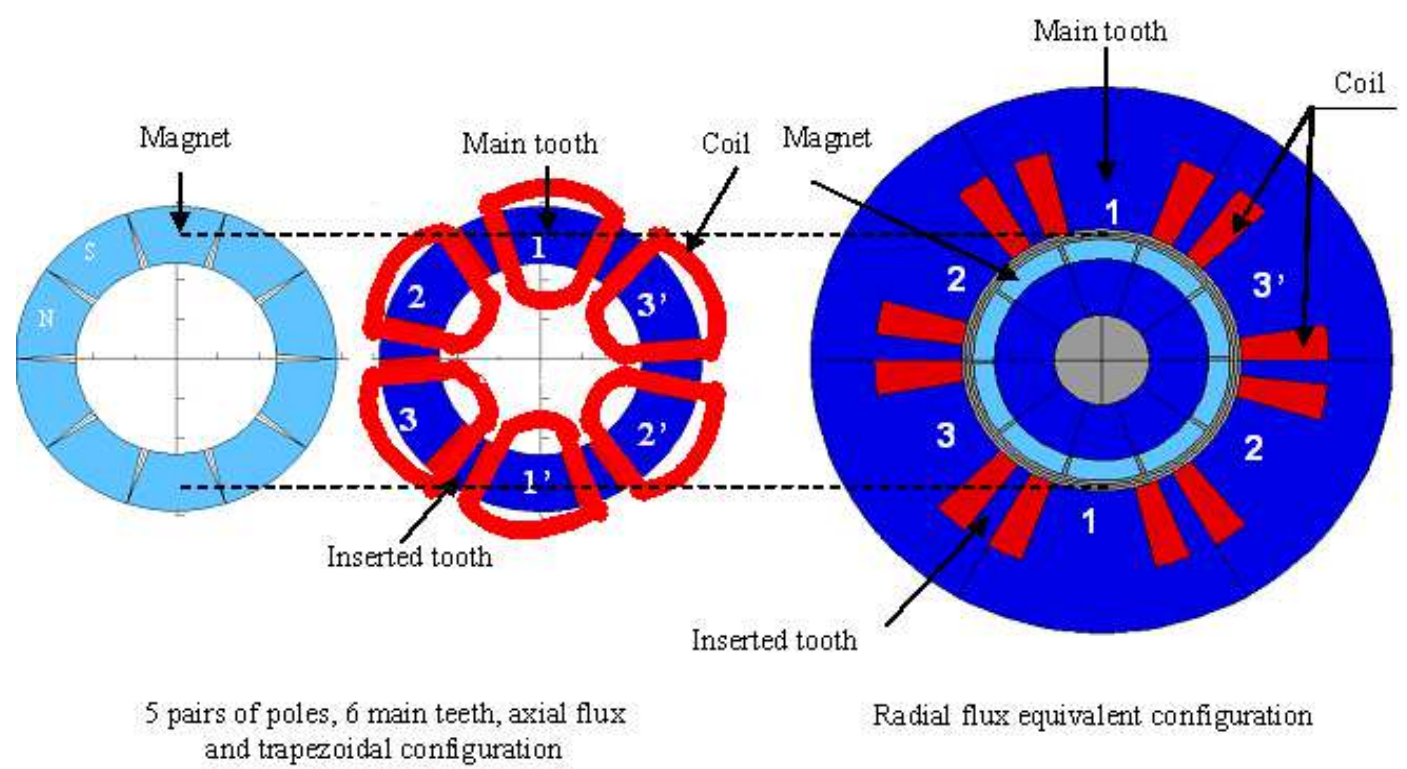

Figure 4. Example of motor configuration.

The design methodology consists of the determination of geometrical and control parameters of the motor-converter improving Autonomy. The motor must function on a broad beach of speed and without demagnetization. This methodology requires the development of an analytical and parameterized model of the all motor-converter. This latter last makes it possible to establish the relation between data, such as: the data of schedule conditions!, the $\left.\right|_{1} ^{1}$ constant characterizing materials, the expert data, the motor configuration and the outputs such as: geometrical and electromagnetic motor magnitudes [8].

This model is validated by finite elements method [8].
Indeed, the motor is drawn according to its geometrical magnitudes extracted from analytical model with the software Maxwell-2d, and is simulated in dynamic and static in order to compare the results obtained with those found by the analytical method.

The coupling of this model to a model evaluating the autonomy poses an optimization problem with several variables and constraints. This latter is solved by the genetic algorithms (GAs) method [9].

The global architecture of the design methodology is illustrated in figure 5 . 


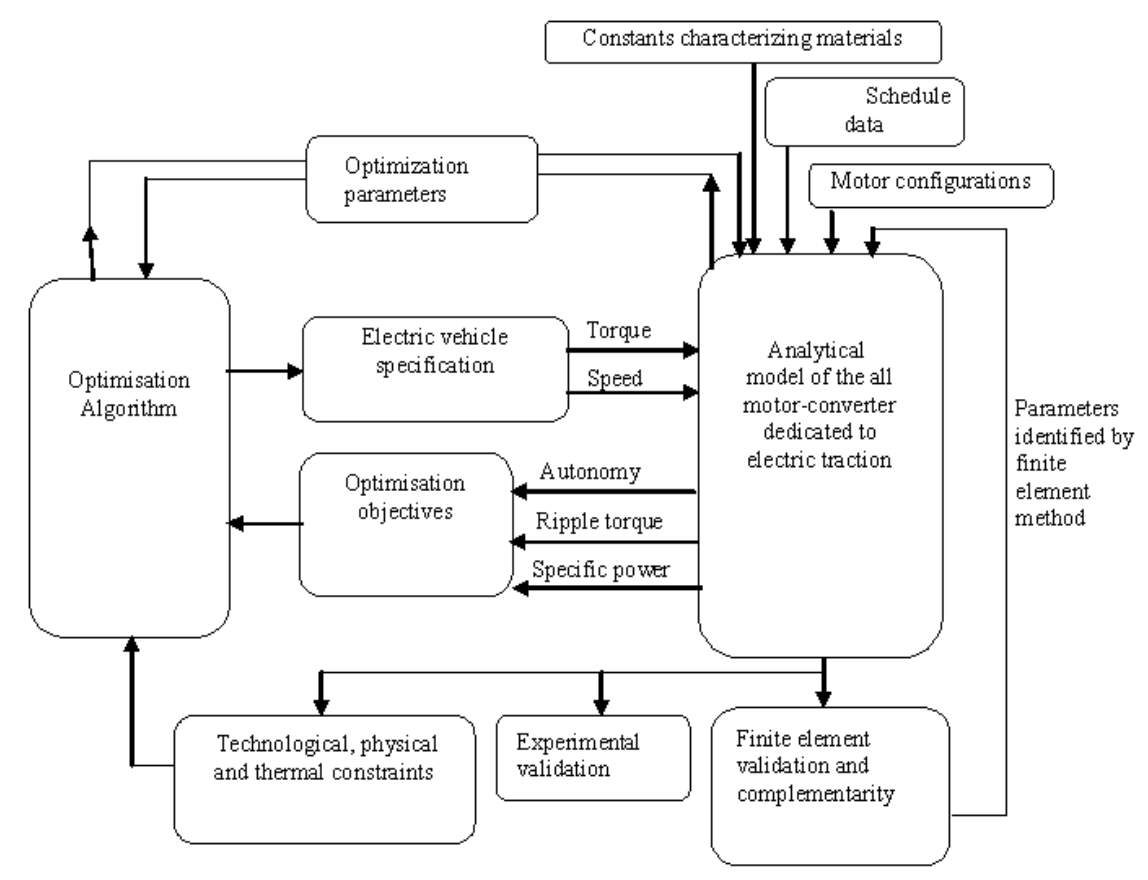

Figure 5. Design methodology of traction motor.

The structure of the motor is modular that is to say multi-stages. The design analytic model of the motor is found on [7].

A thermal nodal model of the electric motor is developed to respect thermals constraints [8]. This thermal model of the motor modular structure is developed while considering that the flux of heat propagates itself axially. The figure 6 illustrates this property:

The nodal model of the motor structure is illustrated by the figure 7:

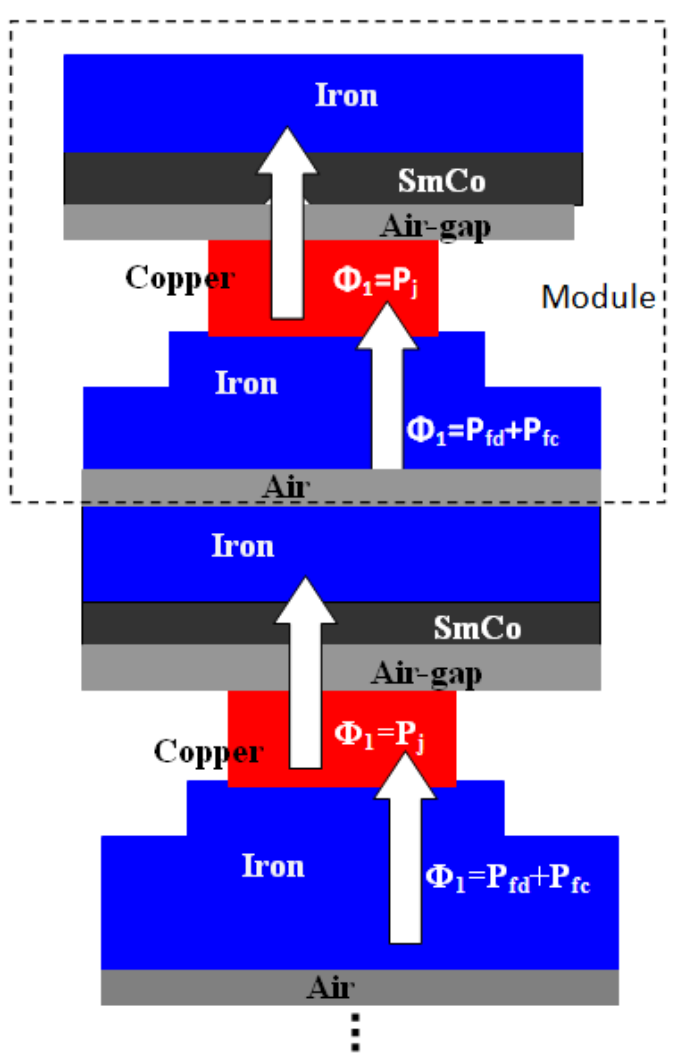

Figure 6. Thermal flux propagation. 


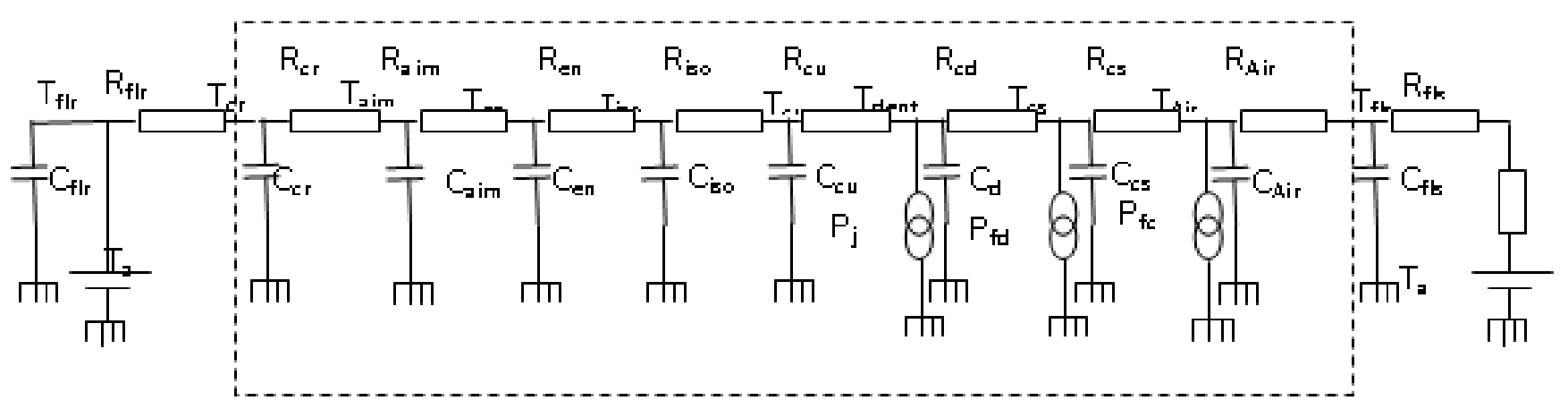

Figure 7. Thermal model of the motor structure.

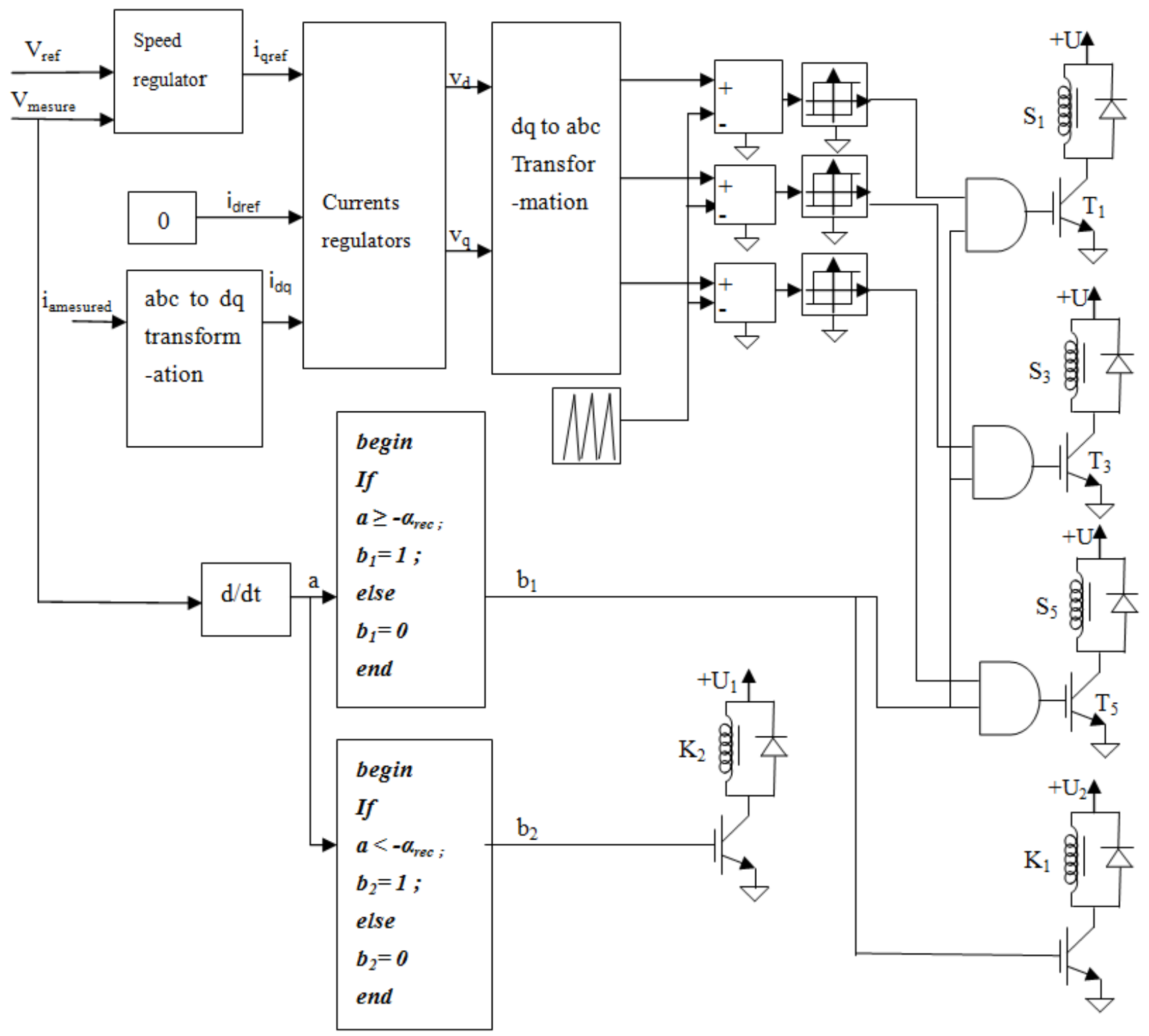

Figure 8. Control generator structure. 
Table 1. illustrates the nomenclature of the nodal model diagram

\begin{tabular}{ll}
\hline $\mathrm{h}_{\mathrm{l}}$ & Free convection coefficient \\
$\mathrm{S}_{\mathrm{r}}$ & Active section of the rotor \\
$\mathrm{h}_{\mathrm{f}}$ & Forced convection coefficient \\
$\mathrm{S}_{\mathrm{s}}$ & Active section of the stator \\
$\mathrm{R}_{\mathrm{cr}}$ & Rotor yoke conduction resistance \\
$\mathrm{R}_{\mathrm{c}}$ & Magnets conduction resistance \\
$\mathrm{R}_{\mathrm{ce}}$ & Air-gap conduction resistance \\
$\mathrm{R}_{\mathrm{cu}}$ & Copper conduction resistance \\
$\mathrm{R}_{\mathrm{cd}}$ & Teeth conduction resistance \\
$\mathrm{R}_{\mathrm{cs}}$ & Stator yoke conduction resistance \\
$\mathrm{R}_{\mathrm{Air}}$ & Air conduction resistance \\
$\mathrm{P}_{\mathrm{i}}$ & Copper losses \\
$\mathrm{P}_{\mathrm{fd}}$ & Teeth iron losses \\
$\mathrm{P}_{\mathrm{fc}}$ & Stator yoke iron losses \\
$\mathrm{T}_{\mathrm{a}}$ & Ambient temperature \\
$\mathrm{T}_{\mathrm{cr}}$ & Rotor yoke temperature \\
$\mathrm{T}_{\mathrm{ai}}$ & Magnets temperature \\
$\mathrm{T}_{\mathrm{en}}$ & Air-gap temperature \\
$\mathrm{T}_{\mathrm{cu}}$ & Copper temperature \\
$\mathrm{T}_{\mathrm{d}}$ & Teeth temperature \\
$\mathrm{T}_{\mathrm{cs}}$ & Stator yoke temperature \\
$\mathrm{C}_{\mathrm{cr}}$ & Thermal capacity of the rotor yoke \\
$\mathrm{C}_{\mathrm{aim}}$ & Thermal capacity of magnets \\
$\mathrm{C}_{\mathrm{en}}$ & Thermal capacity of the air-gap \\
$\mathrm{C}_{\mathrm{cu}}$ & Thermal capacity of the copper \\
$\mathrm{C}_{\mathrm{d}}$ & Thermal capacity of the teeth \\
$\mathrm{C}_{\mathrm{cs}}$ & Thermal capacity of the stator yoke \\
$\mathrm{C}_{\mathrm{AIR}}$ & Thermal capacity of the air \\
$\mathrm{C}_{\mathrm{iso}}$ & Thermal capacity of insulation \\
\hline &
\end{tabular}

\section{Control Generator Structure}

The control generator structure is illustrated by figure 8 .

The control generator assures the transmission of the control signals to the $\mathrm{T} 1$ transistors, $\mathrm{T} 3$ and $\mathrm{T} 5$ dragging the excitation respectively of the three generating windings $\mathrm{S} 1, \mathrm{~S} 3$ and S5 according to the vector control law (Id=0 strategy) during the phases of working to constant speed or in accelerated phase. These three windings attract their cores according to the nature of control signals. Three other windings S2, S4 and S5, no schematized in the control circuit will be powered by signals complementary respectively to the control signals: S1, S3 and S5.

During the energy recuperation phase, b1 signals drags the opening of the DC/AC converter switches and the opening of the K1 switches. b2 signal drags the closing of the K2 switches following the excitation of the $\mathrm{K} 2$ winding. This phase is only possible for decelerations lower to a doorstep where the recuperation is not negligible.

The model of the control generator is implanted under Matlab/Simulink environment (figure 9).

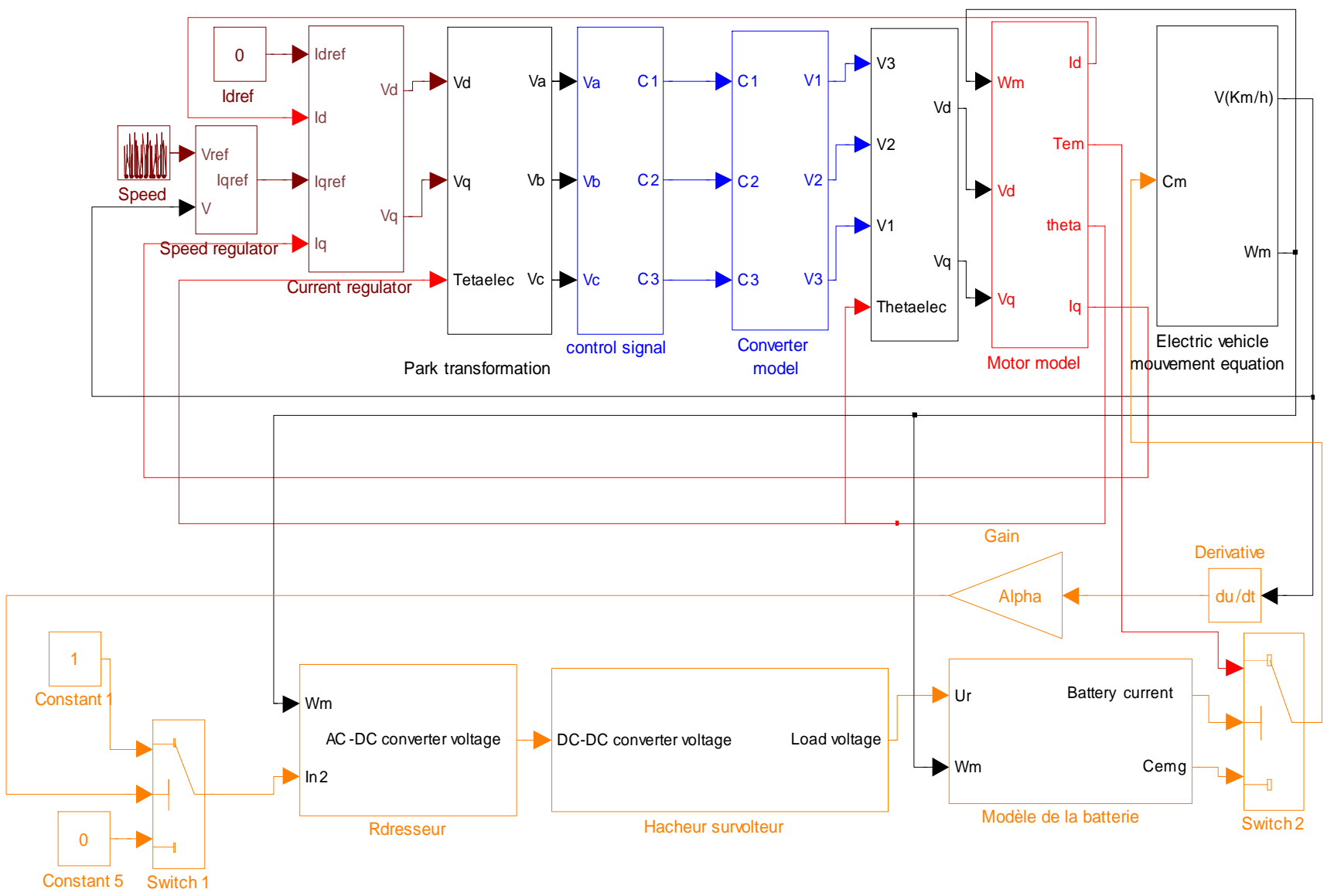

Figure 9. Simulink model of the control generator. 


\section{Generating Winding}

The generating windings assure the closing and the opening of DC/AC converter electromagnetic switches, according to the chosen of control law. When a winding is powered by a sufficient current, it attracts its core and drags the closing of one or switches attached to its Ferro-magnetic core thereafter. The current powering this windings, must be sufficient to defeat the opposite strength generated by the recall spring.

The structure of the generating winding is illustrated by the figure 10:

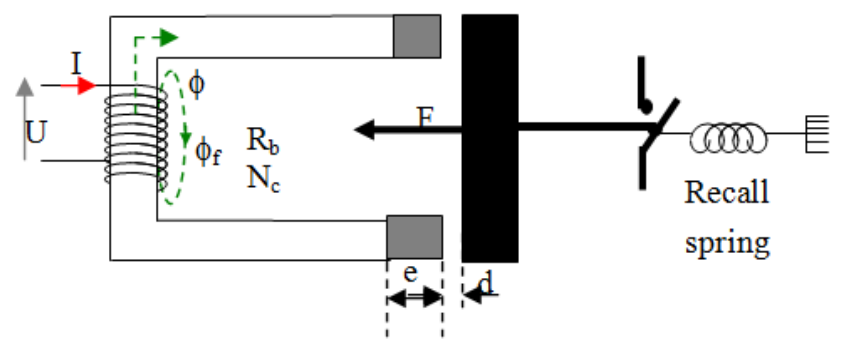

Figure 10. Generating winding.

The generating winding inductance depends on the displacement of the mobile iron core:

$$
\mathrm{L}_{\mathrm{b}}=\frac{\mathrm{N}_{\mathrm{c}}^{2}}{\Re_{\mathrm{t}}}=\frac{\mathrm{N}_{\mathrm{c}}^{2}}{\frac{2 \times \mathrm{e}}{\mu_{0} \times \mathrm{S}}+\frac{2 \times(\mathrm{d}-\mathrm{x})}{\mu_{0} \times \mathrm{S}}}=\frac{\mu_{0} \times \mathrm{S} \times \mathrm{N}_{\mathrm{c}}^{2}}{2 \times(\mathrm{e}+\mathrm{d}-\mathrm{x})}
$$

Where $N_{c}$ is the spires number of winding, $\mu_{0}$ is the air permeability, $S$ is the section of the iron core, $x$ is the displacement of the iron core.

The energy stocked in the winding is given by the following equation:

$$
\mathrm{W}=\frac{1}{2} \times \mathrm{L}_{\mathrm{b}} \times \mathrm{I}^{2}
$$

The power drifting of this energy is given by the following equation:

$$
\mathrm{P}=\frac{\mathrm{dW}}{\mathrm{dt}}=\frac{\mathrm{I}^{2} \times \mu_{0} \times \mathrm{S} \times \mathrm{N}_{\mathrm{c}}^{2}}{4} \times \frac{\mathrm{d}}{\mathrm{dt}}\left(\frac{1}{\mathrm{e}+\mathrm{d}-\mathrm{x}}\right)
$$

This electric power turns into a mechanical power to the level of the mobile iron core:

$$
\mathrm{P}=\mathrm{F} \times \mathrm{V}
$$

Where $\mathrm{F}$ and $\mathrm{V}$ are respectively the attraction strength and the speed of the mobile iron core.

We deduct from the two equations (13) and (14) the expression of the attraction strength depending on the displacement $\mathrm{x}$ :

$$
\begin{aligned}
& \mathrm{F}=\frac{\mu_{0} \times \mathrm{U}^{2} \times \mathrm{S} \times \mathrm{N}_{\mathrm{c}}^{2}}{\mathrm{R}_{\mathrm{b}}^{2}} \times \frac{\mathrm{d}}{\mathrm{dx}}\left(\frac{1}{\mathrm{e}+\mathrm{d}-\mathrm{x}}\right)= \\
& \frac{\mu_{0} \times \mathrm{U}^{2} \times \mathrm{S} \times \mathrm{N}_{\mathrm{c}}^{2}}{\mathrm{R}_{\mathrm{b}}^{2}} \times\left(\frac{1}{(\mathrm{e}+\mathrm{d}-\mathrm{x})^{2}}\right)
\end{aligned}
$$

The equation that describes the working of the mobile iron core and switch, drift of the dynamics fundamental relation:

$$
M_{n} \times \frac{d V}{d t}=F-m \times K \times x
$$

Where $\mathrm{Mn}$ is the mass of the mobile iron core, $\mathrm{K}$ is recall spring constant and $\mathrm{m}$ is the number of attracted switches.

While replacing F by its expression, (16) becomes:

$$
M_{n} \times \frac{d V}{d t}=\frac{\mu_{0} \times U^{2} \times S \times N_{c}^{2}}{R_{b}^{2}} \times\left(\frac{1}{(e+d-x)^{2}}\right)-m \times K \times x
$$

At the balance we have:

$\mathrm{V}=0$ and $\mathrm{d}=\mathrm{x}$, from where we deduct the expression of the powering voltage:

$$
\mathrm{U}=\sqrt{\frac{4 \times \mathrm{m} \times \mathrm{K} \times \mathrm{e}^{2} \times \mathrm{R}_{\mathrm{b}}^{2}}{\mu_{0} \times \mathrm{S} \times \mathrm{N}_{\mathrm{c}}^{2}}}
$$

The active section of the copper depends on the admissible current density in the copper:

$$
\mathrm{S}_{\mathrm{c}}=\frac{\mathrm{I}}{\delta}=\frac{\mathrm{U}}{\mathrm{R}_{\mathrm{b}} \times \delta}
$$

From the equations (18) and (19) we deduct the expression of the active section of winding copper thread:

$$
S_{c}=\sqrt{\frac{4 \times \mathrm{m} \times \mathrm{K} \times \mathrm{e}^{2}}{\mu_{0} \times \delta^{2} \times \mathrm{S} \times \mathrm{N}_{\mathrm{c}}^{2}}}
$$

The generating winding resistance is given by the following equation:

$$
\mathrm{R}_{\mathrm{b}}=\frac{\rho \times \mathrm{L}_{\mathrm{e}}}{\mathrm{S}_{\mathrm{c}}}
$$

Where $\rho$ is the copper resistivity and Le is the winding length:

$$
\mathrm{L}_{\mathrm{e}}=2 \times \mathrm{N}_{\mathrm{c} / \mathrm{c}} \sum_{\mathrm{n}=1}^{\mathrm{N}_{\mathrm{cc}}}\left(\mathrm{a}+\mathrm{b}+2 \times \mathrm{n} \times \sqrt{\frac{\mathrm{S}_{\mathrm{c}}}{\pi}}\right)
$$

Where $\mathrm{Nc}$ is the total number of winding spires, $\mathrm{Nc} / \mathrm{c}$ is the number of thread layer rolled up, a and $b$ are respectively the iron core width and thickness. 


$$
\mathrm{N}_{\mathrm{c} / \mathrm{c}}=\frac{\mathrm{E}_{\mathrm{B}}}{2 \times \sqrt{\frac{\mathrm{S}_{\mathrm{c}}}{\pi}}}
$$

Where EB is the thickness of the copper thread rolled up.

The number of thread by layer is given by the following equation:

$$
\mathrm{N}_{\mathrm{cc}}=\frac{\mathrm{N}_{\mathrm{c}}}{\mathrm{N}_{\mathrm{c} / \mathrm{c}}}
$$

From where the winding resistance is deduced by the following equation:

$$
\mathrm{R}_{\mathrm{b}}=\frac{\rho \times\left(2 \times \mathrm{N}_{\mathrm{c} / \mathrm{c}} \sum_{\mathrm{n}=1}^{\mathrm{N}_{\mathrm{cc}}}\left(\mathrm{a}+\mathrm{b}+2 \times \mathrm{n} \times \sqrt{\frac{\sqrt{\frac{4 \times \mathrm{m} \times \mathrm{K} \times \mathrm{e}^{2}}{\mu_{0} \times \delta^{2} \times \mathrm{S} \times \mathrm{N}_{\mathrm{c}}^{2}}}}{\pi}}\right)\right.}{\sqrt{\frac{4 \times \mathrm{m} \times \mathrm{K} \times \mathrm{e}^{2}}{\mu_{0} \times \delta^{2} \times \mathrm{S} \times \mathrm{N}_{\mathrm{c}}^{2}}}}
$$

\section{Simulation Results}

The model of the losses is implanted under the environment of Matlab/Simulink. The thermal fluxes are calculated while leaning on the inverse gait of modelling of the power chain.

The simulation of the thermal model with a natural ventilation (Coefficient of convection equal to $30 \mathrm{~W} / \mathrm{m}^{2} \mathrm{~K}$ ) and for a working to speed consolidated equal to $80 \mathrm{~km} / \mathrm{h}$, give the evolution of the temperatures in the different active parts of the motor (figure11).

\section{Temperatures $\left({ }^{\circ} \mathrm{C}\right)$}

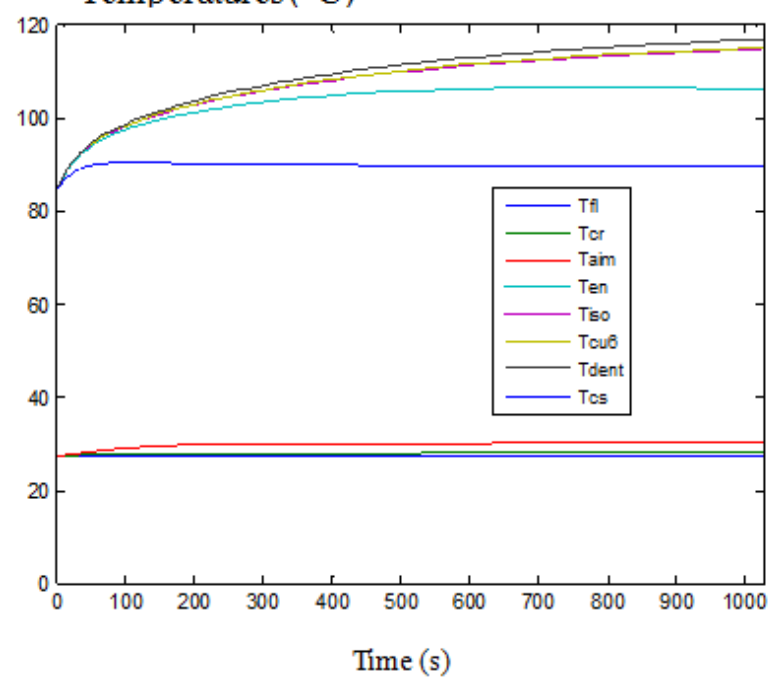

Figure 11. Evolution of the temperatures in the different active parts of the motor for a speed consolidated of $80 \mathrm{~km} / \mathrm{h}\left(\mathrm{h}=30 \mathrm{~W} / \mathrm{m}^{2} \mathrm{~K}\right)$.

Where $\mathrm{Tfl}$ is the average temperature of flabby, Tcr is the average temperature of the rotor yoke, Taim is the average temperature of magnet, Ten is the average temperature of air-gap, Tiso is the average temperature of isolating, Tcu is the average temperature of copper, Tdent the average temperature of stator teeth and Tcs the average temperature of the stator yoke.

This face shows that there is an overtaking of $47{ }^{\circ} \mathrm{C}$ for the copper and the resin, what proves the necessity of a cooling system. Several simulations are thrown for several values of forced convection coefficient to a system of cooling by forced ventilation, led to the fixing of this coefficient to $300 \mathrm{~W} / \mathrm{m}^{2} \mathrm{~K}$.

The evolution of the temperatures in the different active parts of the motor for a working with a system of cooling to forced ventilation with a convection coefficient equal to 300 $\mathrm{W} / \mathrm{m}^{2} \mathrm{~K}$ is illustrated by the figure 12 .

Temperatures $\left({ }^{\circ} \mathrm{C}\right)$

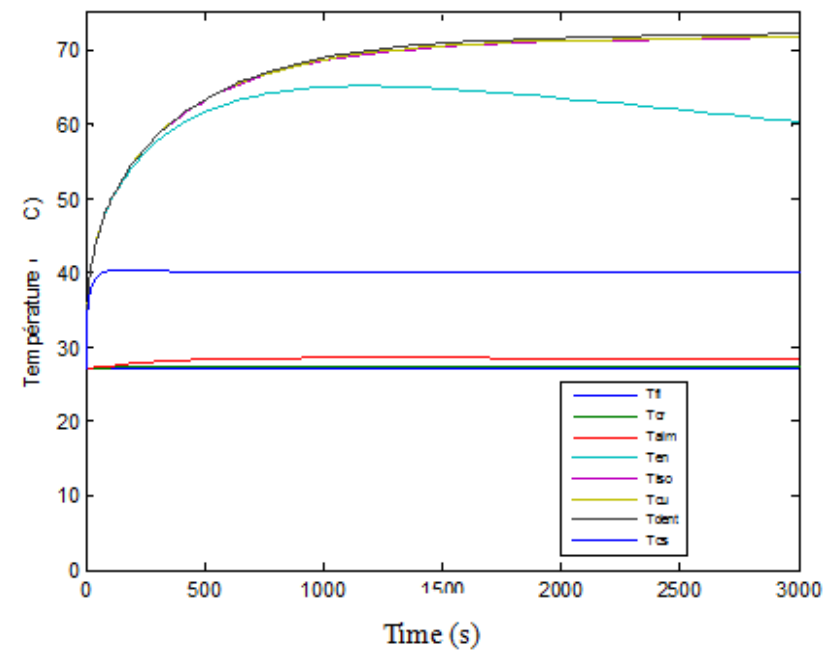

Figure 12. Evolution of the temperatures in the different active parts of the motor for a speed consolidated to $80 \mathrm{~km} / \mathrm{h}\left(\mathrm{h}=300 \mathrm{~W} / \mathrm{m}^{2} \mathrm{~K}\right)$.

The energy recovered (figure 13) believes at the time of the phases of strong decelerations and remain constant during the phases of working in motor.

Recovered energy (kwh)

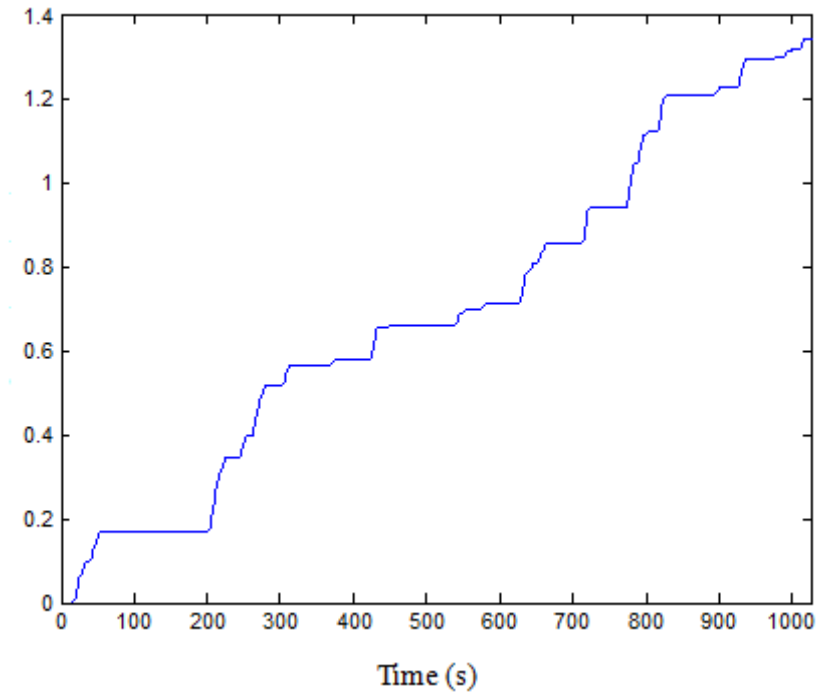

Figure 13. Recovered energy.

This energy is equal in middle value to $0.6942 \mathrm{kw} . \mathrm{h}$ on a 
duration of $1027 \mathrm{~s}$. This value is important, what shows the efficiency of the system of energy recuperation.

\section{Conclusion}

The choice done, the design methodology and control of this power train, increases the autonomy, reliability, considerably. This power train structure presents an attractive solution to solve the problem of the electric vehicles weak autonomies. It's interesting to study the problem of the excessive cost and the problem of battery load infrastructure in future.

\section{List of Symbols}

$\mathrm{Cb} \quad$ Elementary battery capacity

$\mathrm{Ce} \quad$ Electrode armature capacity

$\varepsilon$
Sc Active section of the copper
$\delta \quad$ Current density
Nc Number of winding spires
$\mathrm{Nc} / \mathrm{c} \quad$ Number of thread layer rolled up
Ncc Number of thread by layer
EB Thickness of the copper thread rolled up

\section{References}

[1] Naomitsu Urasaki, Tomonobu Senjyu and Katsumi Uezato: “A novel calculation method for iron loss resistance suitable in modelling permanent-magnet motors", IEEE TRANSACTION ON ENERGY CONVERSION, VOL. 18. NO 1, MARCH 2003.

[2] B. Ben Salah, A. Moalla, S. Tounsi, R. Neji, F. Sellami: "Analytic design of Permanent Magnet Synchronous motor Dedicated to EV Traction with a Wide Range of Speed Operation", Internéational Review of Electrical Engineering (I.R.E.E), VOL 3, NO 1 January-February 2008"

[3] Sid Ali. RANDI : Conception systématique de chaînes de traction synchrones pour véhicule électrique à large gamme de vitesse. Thèse de Doctorat 2003, Institut National Polytechnique de Toulouse, UMRCNRS N 5828.

[4] C. C. Chan and K. T. Chau: "An Overview of power Electronics in Electric Vehicles", IEEE Trans. On Industrial Electronics, Vol, 44, No 1, February 1997, pp.3-13.

[5] C. PERTUZA: "Contribution à la définition de moteurs à aimants permanents pour un véhicule électrique routier". Thèse de docteur de l'Institut National Polytechnique de Toulouse, Février 1996.

[6] S. TOUNSI, R. NEJI, F. SELLAMI: "Contribution à la conception d'un actionneur à aimants permanents pour véhicules électriques en vue d'optimiser l'autonomie". Revue Internationale de Génie Electrique, Volume 9/6-2006, pp. 693-718. Edition Lavoisier.

[7] S. Tounsi : "Modélisation et Optimisation de la Motorisation et de l'Autonomie d'un Véhicule Electrique".Thèse de docteur de l'Ecole National d'Ingénieur de Sfax Tunisie, February 2006.

[8] Sid Ali. RANDI: Conception systématique de chaînes de traction synchrones pour véhicule électrique à large gamme de vitesse. Thèse de Doctorat 2003, Institut National Polytechnique de Toulouse, UMRCNRS N 5828.

[9] S. TOUNSI, R. NEJI and F. SELLAMI : Electric vehicle control maximizing the autonomy: 3rd International Conference on Systems, Signal \& Devices (SSD'05), SSD-PES 102, 21-24 March 2005, Sousse, Tunisia. 